\title{
A Universidade e a organização do conhecimento: a rede, o tácito, a dádiva
}

\author{
NÍLSON JOSÉ MACHADO
}

$\mathrm{N}$

A SOCIEDADE EM que vivemos, o conhecimento transformou-se no principal fator de produção, no elemento fundamental para a produção de riquezas, explicitando-se com muita nitidez sua imediata vinculação com o universo do trabalho. De modo geral, a importância decisiva da Educação para uma justa "distribuição" desse "bem" tem sido reconhecida, e as Universidades, como centros de criação de conhecimento, desempenham, nesse cenário, um papel de destaque.

O fácil acordo no discurso sobre a relevância de tais temas não nos impede, no entanto, de enfrentar uma série de situações desconcertantes, que parecem resultar justamente de uma justaposição acrítica entre esses dois universos o do conhecimento e o da economia. Mesmo sendo considerado um "ativo" em sentido econômico, certamente o conhecimento não pode ser tratado como uma mercadoria em sentido industrial sem a ocorrência de efeitos colaterais insólitos, ou sem a emergência de situações paradoxais, de verdadeiros becos sem saída.

Acrescente-se a isso o fato de que, em um período pleno de debates sobre os limites e as relações entre o espaço público e o privado, nos diversos âmbitos sociais - saúde, educação, pesquisa científica, entre outros - as atenções se voltam naturalmente para a universidade. Ressurgem, então, de tempos em tempos, na mídia, nas vozes ou nos porta-vozes de um liberalismo radical, argumentos que invocam a limitação de recursos públicos e/ou o suposto caráter elitista dos estudos superiores, para questionar o financiamento da universidade pública. Tais argumentos conduzem, inevitavelmente, a um sítio com as feições de um aparente dilema: ou se aumentam significativamente as vagas na universidade pública (gratuita), o que esbarra na limitação de recursos, ou se abandona a idéia de gratuidade, o que poderá acentuar o elitismo que se visaria combater.

Formulada dessa forma limitada, a questão torna-se excessivamente simplificada, beirando o caricato e não atingindo a raiz dos problemas. De fato, em nenhum lugar do mundo a universidade é, em sentido próprio, "gratuita": certamente, os custos do ensino e da pesquisa são financiados de alguma forma, 
direta ou indiretamente, sendo difícil imaginar-se a possibilidade, ou apontar-se exemplos consistentes de situações em que o pagamento direto, por parte dos alunos, seja a solução para as limitações de recursos. Uma análise radical remete, necessariamente, à estrutura do sistema tributário. Áreas como a Saúde e a Educação não podem ter um financiamento equacionado apenas segundo parâmetros mercantis. Não lidam com "produtos" que se pode vender ou comprar a um preço determinado pelo putativo equilíbrio entre a oferta e a procura. O papel do Estado é fundamental, no mínimo para configurar uma teia de tributos que incidam sobre a renda - sobretudo sobre operações financeiras ou sobre heranças, e não sobre salários - tendo em vista a eqüidade na oferta dos serviços de saúde e no financiamento da educação. Mas considerar tais temas, neste momento, significaria um grande desvio dos objetivos da presente reflexão.

De qualquer forma, um tratamento consistente da questão em tela - organização do conhecimento na Universidade - não pode prescindir do exame de outra questão correlata, que diz respeito ao modo como o conhecimento é concebido e organizado, tanto no ensino pré-universitário e nos vestibulares, associados aos mecanismos de acesso à Universidade, quanto no interior da própria Universidade, com a tênue interação existente entre as diversas unidades, os departamentos ou as disciplinas. A própria pesquisa científica parece, com certa freqüência, ilustrar uma crescente fragmentação do saber sem a contrapartida de uma visão abrangente relativa aos valores envolvidos. Em determinadas áreas, transparece uma superestimação muitas vezes acrítica de certas especializações intradisciplinares, que pouco ou nada significam no que tange à promoção da liberdade humana.

Atendo-nos especificamente à concepção e à organização do conhecimento na Universidade, é possível identificar três focos problemas, que buscaremos caracterizar e analisar:

- a assintonia entre os padrões atuais de organização do universo do trabalho, associados ao uso intensivo de tecnologias informáticas, e a estrutura interna das Universidades, tributárias de um cartesianismo radical;

- o desequilíbrio nas relações entre a Educação e a Cultura, com o progressivo deslocamento do centro de gravidade da Universidade do conhecimento em sentido pleno para a formação profissional ou a produção tecnológica;

- a insuficiência do par valor de uso/valor de troca, no que tange à compreensão do valor do conhecimento produzido, ou aos critérios para o financiamento da pesquisa científica.

Para uma reorganização do processo de construção/circulação do conhecimento, particularmente no que se refere ao espaço acadêmico, três idéias podem contribuir para o equacionamento dos problemas supra-referidos: 
- a imagem do conhecimento como uma rede de significações;

- o reconhecimento do valor do conhecimento tácito;

- e a explicitação da dádiva como dimensão do conhecimento.

\section{Conhecimento como rede de significações}

Na organização do conhecimento escolar, em praticamente todos os níveis de ensino, a imagem hegemônica que orienta as ações educacionais é a do encadeamento, matriz do pensamento cartesiano, tão bem caracterizado no livro Discurso do método (Descartes, 1978).

Para Descartes, a construção do conhecimento somente poderia ser confiável se o ponto de partida fosse constituído por "idéias claras e distintas". Assim, diante de uma tarefa complexa, em termos cognitivos, o método, ou o caminho, era um só: decompor, analisar, reduzir o complexo a idéias simples. A conta que se paga por tal redução chega rapidamente: o objeto do conhecimento é reduzido a fragmentos, esvaindo-se seu significado. Diante disso, outra vez, para Descartes, o caminho é um só: reconstituir o objeto por meio de uma enumeração exaustiva de suas partes simples, seguida de um encadeamento lógico entre as mesmas, tendo como elos fundamentais proposições do tipo "se A, então B”.

Quase toda a moldura da cultura ocidental resulta dessa matriz do pensamento cartesiano. Tal fato levou Tocqueville a afirmar, ao analisar o modo de pensar dos americanos, que eles seguem rigorosamente os preceitos cartesianos, ainda que nunca tenham lido ou nunca venham a ler Descartes (Tocqueville, 1977: 321). No solo firme do Discurso, enraízam-se, portanto, no cenário ocidental, as palavras de ordem do discurso educacional, como "pré-requisitos", "seriação", "ordem necessária para os estudos", entre outras. No mesmo sentido, consolidam-se metáforas metodológicas de grande aceitação, como a que associa a construção do conhecimento à construção de uma casa, ou à percepção de uma imagem fotográfica. No primeiro caso, tem-se como um dado $a$ priori que o ponto de partida na construção do conhecimento devem ser os alicerces, as bases, não havendo sentido em se pensar nas paredes ou no teto de uma casa cujas fundações não são confiáveis. Considerar essa metáfora em sentido literal está na origem de tantas reclamações por parte de professores quanto à suposta "falta de base" de seus alunos. No segundo caso, considera-se como fato indiscutível a suposição de que uma foto é construída/percebida ponto a ponto: para ver uma paisagem complexa, seria necessário discernir antes seus pontos/ingredientes; somente então, ponto a ponto, a foto seria composta. Grande parte da linguagem da didática é tributária desta última pressuposição, como é o caso, por exemplo, das "listas de pontos" a serem estudados, em provas ou concursos. 
De modo geral, as máximas cartesianas predominam na organização de todo o sistema escolar, mas sua influência é mais aguda à medida em que se avança para os níveis superiores do ensino. A análise dos livros didáticos utilizados, nas diversas disciplinas, revela certa cristalização de percursos, no tratamento dos conteúdos dos programas, o que conduz a uma aparência de ordem necessária dos assuntos apresentados. A idéia de que alguns assuntos devem ser ensinados antes de outros é freqüentemente superestimada, ignorando-se uma rica diversidade de contextos, de centros de interesse e de possibilidades de percursos. Nos cursos superiores, as palavras de ordem cartesianas têm conduzido, muitas vezes, a um enrijecimento excessivo das estruturas curriculares, reduzindo toda a possibilidade da composição pessoal de um cardápio de estudos a um estreito leque de optativas e não favorecendo uma formação pessoal, ou mesmo uma teia de interações mais efetivas entre as diversas disciplinas componentes dos currículos dos diversos cursos. Os próprios professores organizam-se em Departamentos, cujo significado pode ser apreendido pelo elenco de disciplinas que oferecem, e cuja articulação lógica com os demais departamentos é bastante restrita, limitando-se, quase sempre, a aspectos formais ou administrativos. E as possibilidades de uma convivência acadêmica, de uma interação intelectual efetiva, de uma partilha de conhecimentos tácitos desenvolvidos individualmente no exercício do trabalho acadêmico, ficam restritas a momentos situados à margem da organização do ensino, ou dependentes de situações fortuitas, decorrentes de iniciativas isoladas.

Poucas são as unidades universitárias que escapam a uma caracterização como a que se acabou de esboçar. Na Universidade de São Paulo, por exemplo, o Instituto de Estudos Avançados (IEA) tem uma estrutura significativamente distinta: as áreas que agregam professores e alunos não se caracterizam como departamentos, mas constituem pólos de investigação com temática definida, estando associadas a projetos em andamento. As atividades realizadas são de freqüência livre a todos os interessados, não constituindo cursos formais, como os de graduação. A temática das diversas áreas é, quase sempre, interdisciplinar, e os interesses envolvidos transcendem, seguramente, o âmbito das disciplinas acadêmicas. Não existem, pois, professores ou alunos permanentes, ocorrendo, ao longo dos anos, uma circulação de temas e de pessoas que parece fundamental para a fecundidade das atividades realizadas.

Ocorre, no entanto, que a possibilidade de uma organização alternativa, como a do IEA, decorre exatamente do fato de o mesmo não ministrar cursos regulares - nem de graduação, nem de pós-graduação -, o que reforça a idéia de a estruturação dos cursos formais oferecidos na Universidade estar radicalmente comprometida com os padrões cartesianos de organização. A hegemonia é tão marcante que se chega mesmo a inquirir: poderia ser de outra forma? Sem dúvida, poderia, e o recado está sendo transmitido, continuamente, pela forma como 
o conhecimento se organiza no mundo do trabalho, nos setores de produção. Analisaremos, agora, tal ponto.

Inicialmente, é importante registrar que, sobretudo a partir do século XIX, o mundo do trabalho acolheu, progressivamente, a perspectiva cartesiana como padrão de organização. Na produção de automóveis, a linha de montagem traduzia com perfeição o esmigalhamento de uma tarefa complexa, reduzida à realização de microtarefas, esvaziadas de sentido mas devidamente encadeadas de modo a garantir, em algum sentido, a eficácia da produção. Chaplin captou com perfeição a dimensão caricata de tal redução, explicitando-a em interessante filme, no início do século XX (Tempos Modernos). Nos últimos 30 a 40 anos, no entanto, outros padrões de organização têm ocupado cada vez mais espaço, inspirados, em grande parte, na utilização intensiva de tecnologias informáticas. De modo geral, é possível reconhecer-se uma crescente valorização do trabalho em equipe, do envolvimento coletivo na realização de um projeto, da interação entre os participantes, além de maior flexibilidade/mobilidade na atribuição de tarefas. É nesse cenário que se enraíza e se irradia, tanto em sentido literal quanto em sentido metafórico, a palavra rede.

A idéia de rede constitui uma imagem emergente para a representação do conhecimento, inspirada, em grande parte, nas tecnologias informacionais. Nesta perspectiva, conhecer é como enredar, tecer significações, partilhar significados. Os significados, por sua vez, são construídos por meio de relações estabelecidas entre os objetos, as noções, os conceitos. Um significado é como um feixe de relações. O significado de algo é construído falando-se sobre o tema, estabelecendo conexões pertinentes, às vezes insuspeitadas, entre diversos temas. Os feixes de relações, por sua vez, articulam-se em uma grande teia de significações e o conhecimento é uma teia desse tipo.

Para explicitar a fecundidade da idéia de rede, examinaremos sucintamente algumas de suas características, que podem ser associadas tanto às redes em sentido literal (redes de computadores) quanto à rede como imagem do conhecimento. Tratam-se de palavras-chave, que participam da constituição da imagem da rede tal como as palavras "decomposição", "encadeamento", "pré-requisitos" ou "seriação" participam da imagem da cadeia como metáfora para o conhecimento. Acentrismo, historicidade, heterogeneidade são exemplos de palavras correlatas, associadas à idéia de rede como representação do conhecimento.

Comecemos com o acentrismo. A teia de significados que representa o conhecimento não tem centro. Ou o centro pode estar em toda parte, o que equivale a afirmar a inexistência de um centro absoluto. Como o universo da Cultura, o do conhecimento tem apenas centros de interesse. Nossa atenção é que elege centros, diretamente associados às circunstâncias que nos regulam, às relações que vivenciamos. Para tratar dos mais diversos conteúdos, dentro de 
cada disciplina ou em temas transdisciplinares, não existe algo como um ponto de partida necessário, nem um único caminho a ser seguido. Múltiplas são as portas de entrada na rede de significações e partilhá-las é o que importa: a porta por onde se adentrou à rede perde-se na memória. Múltiplos são os percursos possíveis, na estruturação, no planejamento dos trabalhos de uma disciplina ou de um curso. Tais pontos de vista, no entanto, permanecem muito distantes da organização da escola, em seus diversos níveis. A imagem do encadeamento, da ordem necessária para a apresentação dos conteúdos permanece amplamente hegemônica. Predomina a idéia da existência de caminhos necessários, de uma ordenação padronizada, da superestimação da pressuposição da existência de temas que devem ser ensinados/aprendidos na série adequada, em determinada idade. Os currículos e os livros didáticos, de modo geral, reforçam tal perspectiva, cristalizando percursos e alimentando a impressão da necessidade de uma ordem igual para todos os contextos. No caso da Universidade, a introdução de disciplinas optativas constitui, em geral, apenas um paliativo: os currículos permanecem essencialmente como encadeamentos rígidos, que limitam os alunos mais criativos e punem os "dissidentes".

Uma segunda característica importante das redes de significações como imagem do conhecimento é o fato de elas estarem em permanente estado de atualização, ou de sua natural historicidade. Continuamente, relações são incorporadas à rede, ou são abandonadas por não refletirem mais articulações vivas entre os objetos ou os temas envolvidos. Em outras palavras, a construção do conhecimento é permanente, é viva, nunca se pode fundar em definições fechadas, nunca é definitiva. A contínua metamorfose, ou a natural historicidade dos conceitos é uma regra fundamental.

Um professor de Matemática, por exemplo, que pretende introduzir a idéia de logaritmo, hoje, recorrendo a características do tema como a transformação de multiplicações em adições, ou, de modo geral, à simplificação de cálculos, provavelmente não será entendido pelos alunos: com tantos instrumentos para a realização de cálculos, quem poderia estar interessado em um recurso tão pouco natural como os chamados "logaritmos naturais"? Atualmente, os logaritmos constituem um tema mais importante, talvez, do que no século XVII, quando foi desenvolvido. Mas o feixe de relações que caracteriza tal idéia é, hoje, fundamentalmente distinto. A simplificação de cálculos tornou-se um coadjuvante menor. O protagonismo fica por conta de crescimento ou decrescimento de grandezas que variam em um espectro muito largo, e que são convenientemente representadas por potências de 10, ou de outra base qualquer. Os logaritmos, que são apenas um nome extravagante para "expoente", constituem elementos fundamentais nessa linguagem "exponencial", associada à determinação da magnitude de terremotos (Escala Richter), ao caráter ácido ou básico de uma solução $(\mathrm{pH})$, às intensidades sonoras (decibel), ou ao crescimento ou 
decrescimento exponencial de certa quantidade de uma substância radiativa. Todas as escalas logarítmicas anteriormente mencionadas têm origem no século $\mathrm{XX}$, constituindo elementos fundamentais no feixe de relações que caracteriza, atualmente, a idéia de logaritmo.

É importante mencionar que o caso dos logaritmos não apresenta qualquer excepcionalidade: de uma forma ou de outra, a necessidade de atualizações de significado constitui a regra geral. Tal fato, no entanto, não pode servir para desestruturar nossas crenças, ou mesmo relativizá-las de modo absoluto. Os significados evoluem e podem transformar-se mas o argumento básico em defesa de sua construção na perspectiva de que sejam eternos - enquanto durem - é o fato de que as próprias transformações de significado têm significado. As redes de significações não se metamorfoseiam aleatoriamente, ou como um caleidoscópio. Para apreender o sentido das transformações, o caminho é um só: é preciso estudar História. Ninguém pode ensinar qualquer conteúdo, das ciências às línguas, passando pela matemática, sem uma visão histórica de seu desenvolvimento. É na História que se podem perceber as razões que levaram tal ou qual relação, tal ou qual conceito, a serem constituídos, reforçados ou abandonados. É na História que buscamos o significado das transformações de significado.

A despeito de tal fato, em todos os níveis de ensino, a relevância da História não parece proporcional a sua importância efetiva na construção do conhecimento. Particularmente na Universidade, muito além do âmbito dos historiadores profissionais, ou dos que se debruçam sobre uma temática fecunda, ainda que, muitas vezes, autocentrada, como costuma ser a História da Ciência, os estudos históricos deveriam ocupar um espaço cada vez maior. Tanto como fonte de inspiração para a compreensão da contínua transformação de significados das idéias, das noções, dos conceitos, quanto como antídoto para o fascínio da tecnologia, com seu visceral desprezo pelo passado.

Uma terceira característica das redes como imagem do conhecimento é a heterogeneidade. A imagem da rede continuamente nos lembra de que os nós/ significados são naturalmente heterogêneos, no sentido de que envolvem relações pertencentes a múltiplos conteúdos, a diversas disciplinas. As noções, os conceitos realmente relevantes sempre terminam por ultrapassar as fronteiras disciplinares. Um conceito como o de "semelhança" pode ser apresentado pelo professor de Matemática a seus alunos de maneira estritamente disciplinar: os casos de semelhança de triângulos são examinados de modo analítico, operam-se classificações e demonstram-se teoremas ou relações entre os elementos envolvidos, exemplifica-se ... e passa-se a outro tema. Certamente tal tratamento é possível, ainda que sempre signifique um empobrecimento no significado da noção em tela. De fato, a idéia de semelhança pode ser naturalmente associada com fotografias, ampliações, reduções, maquetes, mapas, com relações de proporcionalidade entre partes do corpo humano, entre outros temas. 
Insistimos em que, em termos disciplinares, a heterogeneidade é a regra geral e toda tentativa de homogeneização é artificialmente construída. Uma criança com quatro ou cinco anos começa a interessar-se por letras e números mais ou menos simultaneamente, sem distinções disciplinares do tipo "letra é português, número é matemática"; à medida em que avança no processo de escolarização, as fronteiras disciplinares tendem a ser crescentemente demarcadas. Paulatinamente, o conhecimento escolar organiza-se em compartimentos disciplinares, a ponto de, sobretudo a partir da segunda metade do ensino fundamental, a disciplina que se ensina passar a ser o canal de comunicação decisivo na relação professor/aluno, no processo de ensino/aprendizagem. Se nas séries iniciais somos professores de crianças, a partir da $5^{\text {a }}$ série passamos a ser professores de matérias, de disciplinas. E além de perdermos o contato com o aluno como pessoa, contribuímos para acentuar um estágio de fragmentação do conhecimento, de esmigalhamento do sentido que se torna bastante explícito por ocasião dos exames vestibulares. Na Universidade, tal tendência pode ainda acentuar-se, agravada pela fraca interação entre algumas das Unidades ou Departamentos que receberão os alunos, e pelo crescente convívio de professores e alunos apenas com "especialistas” de temáticas contíguas.

Outras características das redes poderiam ser mencionadas, mas vamos nos limitar às três já citadas: acentrismo, historicidade e heterogeneidade. A imagem do conhecimento que se constrói de acordo com tais características é fundamentalmente distinta do encadeamento linear cartesiano, e a organização das ações docentes, como o planejamento ou a avaliação, está diretamente associada à imagem subjacente. Uma superação da excessiva fragmentação disciplinar, da rigidez na estruturação dos currículos, da redução nos espaços do conhecimento aos limites das salas de aula, da estreiteza no espectro de instrumentos de avaliação é favorecida, seguramente, pela consideração da imagem da rede na representação do conhecimento.

No caso específico da Universidade, a contínua reconfiguração das disciplinas no mapeamento do conhecimento nem sempre se encontra em sintonia com a rígida estruturação em departamentos. Nos cursos de pós-graduação, no mapeamento de interesses dos pesquisadores, as áreas de atuação e as linhas de pesquisa costumam ser mais ágeis, funcionando como "cartas móveis", como mapas continuamente atualizáveis. Nos cursos de graduação, em geral, tal mobilidade está longe de se realizar.

O caso do Programa de Pós-Graduação da Faculdade de Educação da USP (FEUSP) pode constituir um exemplo interessante de ser analisado. Os três Departamentos que constituem a FEUSP - Ciências da Educação, Metodologia e Administração Escolar - operam em territórios muito bem demarcados, agregando os professores em torno de disciplinas específicas, ministradas, ano após ano, com fracas interações, como ocorre na maior parte das Unidades. A 
organização do Programa de Pós-Graduação - mestrado e doutorado - segue, no entanto, um padrão diferente: os professores organizam-se em nove Áreas Temáticas, que podem agregar membros de diferentes Departamentos em torno de uma problemática comum, caracterizada por algumas linhas de pesquisa. Um mesmo professor pode participar de mais de uma Área Temática, o que ocorre efetivamente com boa freqüência. E além disso, na composição do cardápio disciplinar dos pós-graduandos, não existe qualquer disciplina obrigatória: a escolha por parte dos alunos, devidamente aconselhados pelo Orientador, deve decorrer da sintonia com o projeto que está sendo realizado.

Trata-se, portanto, de um padrão de organização do conhecimento muito interessante pelas possibilidades de composição de uma trajetória pessoal para cada estudante, o que parece extremamente desejável. Tal padrão é pouco comum nos diversos cursos na Universidade, situando-se muito distante do que corresponde à quase totalidade dos cursos de graduação - inclusive nos que são realizados na FEUSP.

\section{Universidade, cultura, conhecimento tácito}

São duas as características mais marcantes - e conflitantes - da organização do conhecimento na escola, sobretudo na Universidade: em primeiro lugar, há as pressuposições cartesianas de decomposição e encadeamento, como foi anteriormente examinado; em segundo lugar, há a pretensão anticartesiana de objetividade do conhecimento, que atribui pouco ou nenhum valor ao chamado "conhecimento subjetivo". À medida em que, para Descartes, todo conhecimento deriva do sujeito pensante, ou "existo porque penso", filósofos alinhados com as correntes mais prestigiosas do neopositivismo buscaram sanar tal "deficiência" do cartesianismo, estabelecendo as bases firmes de um "conhecimento objetivo". É precisamente este o título de um denso e influente livro de Popper - Objective knowledge-, com diversas versões em português. Desqualificando inteiramente a componente pessoal do conhecimento, Popper (1975: 77) afirma: "simplesmente não existe conhecimento subjetivo puro, genuíno, ou não adulterado".

Existe algo de paradoxal, ou mesmo de esquizofrenia, na convivência dessas duas características do conhecimento, ambas hegemônicas relativamente a outros pontos de vista. Como se sabe, para corrigir o "desvio" cartesiano, Popper postulou a existência de três mundos: o mundo 1 , chamado mundo físico; o mundo 2, de nossas experiências pessoais conscientes, relativas ao mundo 1; e o mundo 3 , que é o dos conteúdos lógicos dos livros, das bibliotecas, das memórias dos computadores etc., único lugar do conhecimento "objetivo". Todo conhecimento do mundo 2 (conhecimento "subjetivo") seria, segundo o autor, dependente de teorias formuladas lingüisticamente no mundo 3 , onde sobrevivem as máximas cartesianas de decomposição e encadeamento lógico. 
Uma perspectiva inteiramente diversa é a de Polanyi, em sua obra fundamental intitulada Personal knowledge (1958), que permanece sem versão em português. Para Polanyi, o conhecimento é sempre pessoal, nunca pode ser reduzido às representações do mesmo codificadas em livros ou organizadas em teorias. Cada um de nós, sobre qualquer tema, sempre sabe muito mais do que consegue codificar ou explicitar em palavras. Em seu instigante livro, Polanyi expressou tal fato representando o conhecimento pessoal como um grande iceberg: a parte emersa seria o que é passível de explicitação e o montante submerso correspon-deria à dimensão tácita do conhecimento, que sustenta o que é explícito ou explicitável. Um atleta, por exemplo, pode demonstrar uma extrema competência na realização de determinada prova, ainda que não consiga explicar em palavras as ações que realiza. Por razões análogas, um aluno pode conhecer um assunto e não ter um bom desempenho em uma prova, ou simetricamente, alguém pode discorrer de modo pertinente sobre valores sem apresentar uma prática minimamente consentânea com os mesmos.

De acordo com Polanyi (1983: 95), a necessária convivência e o equilíbrio dinâmico entre as dimensões tácita e explícita do conhecimento constituem uma característica humana fundamental. Ainda que ele rechace com veemência a identificação, no ser humano, do tácito com o inconsciente e do explícito com o consciente, é possível, no entanto, estabelecer uma comparação entre as relações tácito/explícito e consciente/inconsciente. De fato, elementos ou motivações inconscientes são inerentes à constituição de todo ser humano, orientando sem determinações as ações ordinariamente realizadas, e não é possível vislumbrar a existência de um indivíduo são cuja unidade/totalidade possa ser caracterizada apenas pela sua dimensão consciente. De modo análogo, a permanente interação entre as componentes tácita e explícita do conhecimento não constituem um "defeito" do ser humano, mas um elemento distintivo imanente, especialmente importante e freqüentemente subestimado.

Na perspectiva de Polanyi, a organização do conhecimento na escola concentra-se excessivamente no explícito, no que é verbalizável, ainda que nunca venha a ser plenamente sentido ou vivenciado pelos sujeitos. As atividades escolares privilegiam o explicitável, tanto no desenvolvimento dos trabalhos quanto nos processos de avaliação, sendo freqüente os casos em que conteúdos disciplinares são transmitidos pelos professores - e devolvidos pelos alunos nas provas - sem que ocorra uma "incorporação" efetiva, que é caracterizada por Polanyi por meio de um neologismo: indwelling. Uma tradução aproximada de indwell poderia ser "residir em": o conhecimento escolar freqüentemente não chega a "residir" no aluno, que o recebe e o devolve apenas no âmbito do explícito.

Em outras palavras, os conteúdos disciplinares normalmente examinados o são na forma escrita, expressos por meios lingüísticos ou lógico-matemáticos, permanecendo ao largo todos os elementos subsidiários que necessariamente os 
sustentam. Na organização das ações docentes seria necessário considerar-se que tão importante quanto alimentar o conhecimento explícito é sua incorporação efetiva por parte dos alunos. Além disso, numa perspectiva de extração, ou de edução, que se aproxima da maiêutica socrática, a tarefa básica do professor seria a construção de estratégias de emergência de conhecimentos tácitos, resultantes tanto de atividades escolares quanto de vivências fecundas em ambientes extra-escolares.

Nas empresas, a importância do conhecimento tácito já vem se explicitando há algum tempo. Nos últimos dez anos, muitos livros sobre economia ou administração trazem no título a palavra "conhecimento" ou outra correlata: "Conhecimento empresarial", "Capital intelectual”, "Criação do conhecimento na empresa", "Conhecimento como um ativo" são apenas alguns exemplos. Em quase todos eles, os livros de Polanyi são citados, com maior ou menor intensidade, quase sempre em um contexto de valorização do conhecimento que vai além das tarefas costumeiramente realizadas. E dado que a partilha do tácito não pode ser considerada uma atividade espontânea, busca-se arquitetar estratégias de emergência, em ambientes variados. Nas escolas regulares, tais preocupações ainda parecem muito distantes, tanto no que se refere ao conhecimento dos alunos quanto no que diz respeito ao dos professores.

No que tange à organização do conhecimento na Universidade, a necessidade da busca de uma relação mais adequada entre o tácito e o explícito revelase principalmente no problemático equacionamento das relações entre os elementos do par Cultura/Educação.

De fato, a Cultura é o natural sítio do tácito, onde a arte e os valores são incorporados, cultivados e partilhados. Certamente, em termos culturais, existem momentos de explicitação, como são as festas, os rituais, as exposições, as comemorações de diferentes naturezas, visando a explicitar valores partilhados. Tais momentos, no entanto, constituem apenas a ponta do iceberg: o fundamental subjaz, tacitamente. Se tudo se comemora, nada é comemorado; se todos os momentos são de festa, descaracteriza-se o festejar; e o excesso de rituais conduz, freqüentemente à banalização dos mesmos.

Atualmente, a Universidade parece imediatamente associada à produção científica que gera tecnologia, sendo possível ouvir-se defesas enfáticas da necessidade de uma sintonia fina entre a formação universitária e a preparação para $\mathrm{o}$ trabalho, ou entre a produção acadêmica e a geração de tecnologias. É importante lembrar, no entanto, que tal instituição nasceu diretamente relacionada à preservação da Cultura e neste sítio manteve seu centro de gravidade por muitos séculos. Apenas a partir da Revolução Industrial do século XVIII, com o surgimento das primeiras escolas superiores de formação profissional, iniciou-se um lento deslocamento de tal centro de gravidade no sentido da preparação para o mundo do trabalho e da produção de tecnologias diretamente relacionadas com o mesmo. 
A subestimação do papel da Cultura é tão nítida que, nas formas de estruturação mais freqüentes, a organização da Universidade reserva uma relação mais direta com a Cultura a uma de suas várias pró-reitorias. Além disso, a chamada Pró-Reitoria de Cultura e Extensão divide suas atenções com outro componente, epistemologicamente difuso, como é a extensão de serviços à comunidade.

Sem dúvida, tal como o tácito é subvalorizado em benefício do explícito, a Cultura perdeu terreno na organização da Universidade. Muitas energias são empregadas para garantir-se uma nem sempre entendida indissociabilidade entre o ensino, a pesquisa e a extensão de serviços à comunidade, enquanto é apenas tangenciada outra indissociabilidade, realmente fecunda e decisiva, que é a que deve existir entre a Cultura e a Educação. Questões menores do ponto de vista epistemológico, como são as polarizações formação geral/formação específica, ou "cultura geral" / conteúdo disciplinar, não passam de situações particulares da questão de fundo: tal como não se pode falar de projetos sem uma arquitetura de valores que os sustentem, nem de transformação sem a consciência do que deve ser conservado, não se pode falar em Educação sem Cultura, nem de Cultura sem Educação.

A diminuição relativa da importância da Cultura na Universidade, com o deslocamento do foco das atenções para a formação profissional e para o desenvolvimento tecnológico simboliza, em outro nível, a progressiva subsunção do conhecimento em sentido amplo - que inclui a arte como uma forma de conhecer, por exemplo - pelo chamado conhecimento científico, e mais fragmentadamente ainda, pelo conhecimento disciplinar. A palavra "cientista" foi utilizada pela primeira vez no século XIX; antes, não havia "cientistas", mas sim filósofos, que buscavam a sabedoria em sentido amplo. Hoje, os cientistas mais valorizados são os que ostentam um rótulo adicional de "especialista" em uma disciplina, ou em uma subdisciplina, ou em fragmento ainda menor de uma componente disciplinar. A necessidade de uma visão transdisciplinar integradora faz-se notar em todos os terrenos, revelando-se em indícios como o seguinte: ao mesmo tempo em que as pesquisas correspondentes ao Projeto Genoma ocupam páginas e páginas de jornais e revistas, nunca se falou tanto, nos mesmos meios, de Bioética, nunca se reivindicou tanto a necessidade de uma reflexão sobre valores no terreno da produção científico-tecnológica.

Nos últimos anos, um número crescente de empresas tem concentrado suas atenções na preparação direta de seus próprios profissionais, constituindo o que tem sido chamado de "Universidades Corporativas". Tal expressão pressupõe, sem dúvida, certa tolerância terminológica que não nos cabe examinar aqui: mesmo com todo o estímulo ao desenvolvimento das instituições privadas de ensino superior, o próprio Ministério da Educação mantém certos critérios mínimos para regular o uso da palavra "universidade". Voltando ao ponto que aqui importa analisar, dificilmente uma universidade pública, por exemplo, pode 
disputar com uma empresa " $X$ " a chancela de uma preparação mais adequada de profissionais para os quadros da própria empresa. Entretanto, na formação de um verdadeiro profissional, tanto quanto a competência técnica, contam a sustentação da mesma por uma arquitetura de valores socialmente acordados, que conduzem a um compromisso público relacionado com a competência que se professa, como também certo nível de auto-regulação profissional, a qual funciona como o correlato da autonomia do cidadão, no âmbito do exercício de uma atividade remunerada. Sem tais ingredientes, a formação "universitária” se reduz ao desenvolvimento de uma competência técnica que, por mais sofisticada que possa parecer, não distingue o profissional do mercenário, ou a uma ausência de compromissos outros que não os assumidos com os próprios pares, o que reduz o profissionalismo a uma de suas caricaturas - o corporativismo. Em uma universidade corporativa, portanto, o espectro de valores que orienta os projetos é, em geral, muito estreito, limitando-se aos objetivos econômicos, aos projetos empresariais ou aos interesses que a sustentam.

Resumindo, afirmamos que, ainda que não se possa diminuir a importância da Universidade na formação profissional e na geração de tecnologias, é na construção coletiva de uma arquitetura de valores em sentido amplo que a função da Universidade se revela fundamental e insubstituível. A associação da reflexão acadêmica a uma espécie de "inteligência" nacional, matriz de onde derivará a diversidade de projetos coletivos que constituem a vida e a autonomia do país, não pode ser compreendida sem uma relação direta com a germinação dos valores que sustentarão tais projetos. Uma “inteligência", mesmo que possa ser caracterizada como "científica", não pode carecer de uma arquitetura de valores, cultivados tacitamente na prática acadêmica, e que compõem um espectro muito mais amplo do que o dos valores econômicos ou empresariais.

\section{Conhecimento, dádiva, valor de laço}

Partimos do fato de que, hoje, o conhecimento é a grande riqueza e a Educação é o principal instrumento para sua "distribuição". No mundo inteiro, no entanto, de forma aparentemente caprichosa, nunca se valorizou tanto a Educação no nível do discurso e nunca as desigualdades na distribuição das riquezas cresceram tanto, em todos os setores. Na mídia, nos meios artísticos, nos esportes, vivenciam-se situações de disparidades de remuneração por tarefas nominalmente equivalentes que beiram o paroxismo: segundo o chamado star system, o "vencedor" leva tudo; o segundo lugar é o primeiro dos "perdedores". Similarmente, em todo o universo do trabalho, ao mesmo tempo em que o desemprego é considerado o mal do fim do século (ou do início do novo século), o excesso de trabalho também o é: quem está fora do grande laço em que o mercado se tornou, cada vez tem mais dificuldades para adentrá-lo; quem está dentro, se esfalfa ansiosamente para não sair dele. 
Especificamente no que se refere ao conhecimento, a despeito de facilidades crescentes para a produção de livros ou de softwares como instrumentos de socialização e de facilitação do acesso aos mais variados saberes, é crescente a concentração do poder de distribuição em um pequeno número de empresas, acentuando as desigualdades por meio de um sufocamento dos pequenos produtores (editoras, por exemplo).

Na verdade, não parece haver qualquer capricho nesse aparente paradoxo. O fato é que a grande riqueza que o conhecimento representa ainda não encontrou, no universo da Economia, um tratamento adequado a suas peculiaridades. Na condição de um "bem", de um "ativo", de um fundamental fator de produção, o conhecimento apresenta características bastante distintas daquelas de uma mercadoria em sentido industrial. Enquanto a economia industrial trabalha e projeta na perspectiva da obsolescência, do desgaste pelo uso, da efemeridade e de reposições em períodos cada vez menores, o conhecimento é um bem que não é fungível, que quanto mais “uso", mais novo fica. É certo que, freqüentemente, se ouvem cantilenas emitidas por entusiasmados defensores da economia de mercado, argumentando sobre a importância da Educação com base em afirmações do tipo "até o ano de 2010 , a quantidade de conhecimento no mundo dobrará a cada 80 dias", ou então, "seis meses depois de formados, metade do nosso conhecimento evaporou-se, perdeu o sentido". Tratam-se, no entanto, de equívocos terminológicos, de usos inadequados de termos como conhecimento ou Educação. No exemplo anteriormente citado, é evidente a confusão entre "dados" ou mesmo "informações" e "conhecimento". É muito fácil, por exemplo, dobrar um banco de dados, ou mesmo, a quantidade de informações sobre qualquer tema. Assim como é verdade que a fragmentação e a efemeridade constituem a natureza da informação. Mas o conhecimento é mais do que o mero acúmulo de dados, ou a mera justaposição de informações datadas. Falar de conhecimento é falar de teorias, não em sentido formal, mas em sentido lato, mais próximo da raiz etimológica que associa a teoria a uma visão organizada que leva à compreensão.

Nesse sentido, é muito difícil falar-se em "acúmulo" de conhecimento, de "nível" de conhecimento. As visões transformam-se, os cenários se reconfiguram, e se no âmbito dos instrumentos da produção tecnológica existe certo consenso sobre a idéia de progresso, no que se refere às relações humanas, às instituições políticas, às artes, ou em geral, à Cultura, o mesmo não pode ser dito. Em que sentido se pode comparar o "nível” de conhecimento de Aristóteles com o de um cientista do século XXI? Em que situação, mesmo no cenário científico, seria possível caracterizar-se um progresso linear que possibilitasse uma contabilidade do tipo "dobrar" a quantidade de conhecimento? Como comparar o "nível" da música, ou da arte, em geral, do século XVIII com a dos dias atuais? 
Analogamente, se na economia a lei da oferta e da procura regula os preços, e o controle dos estoques é um elemento fundamental, no caso do conhecimento, não se pode falar propriamente em "estoque", ou ele não pode ser considerado finito. De fato, o conhecimento é um "bem" que posso vender, doar ou trocar sem ter de ficar sem ele, o que conduz a contabilidade econômica a verdadeiros paradoxos. Esconder o que se conhece para aumentar o valor do que se sabe, ou controlar excessivamente a circulação de certo "conhecimento", tendo em vista aumentar seu preço, pode produzir, no âmbito da economia do conhecimento, um efeito contrário ao desejado. Existem diversos exemplos de grandes empresas que fizeram apostas nesse sentido e hoje são consideradas decididamente equivocadas.

$\mathrm{Na}$ verdade, o par valor de uso/valor de troca parece insuficiente para uma compreensão satisfatória do modo como o conhecimento naturalmente circula entre "produtores" e "consumidores". Existe uma multiplicidade de situações em que os papéis referidos são diluídos entre os participantes da teia de relações significativas, e os significados do trabalho e da própria vida em sentido pleno podem ser associados a um permanente movimento entre o aprender e o ensinar. Essa é, por exemplo, a perspectiva de Schaff (1990), para quem, numa sociedade informática, "o significado do trabalho é a Educação".

A estrita troca de equivalentes e o sentido puramente utilitário não podem explicar o que se passa no universo das relações entre professores e alunos, muito menos o significado da vida, das artes, ou ainda, da filosofia ou da religião. Qual a utilidade de uma criança, de um poema, de uma música? Quanto valem um sorriso, um abraço, um rim, um coração? Como distinguir os âmbitos em que o valor se sobrepõe ao preço ou o preço é indício de valor?

Nas economias pré-mercantis, a forma básica de circulação de bens era a dádiva, eram os presentes: dar, receber, retribuir eram os instrumentos para a criação de laços, para o estabelecimento da harmonia. Paradoxalmente, o ato de dar, que é sempre uma demonstração de superioridade em algum sentido, é a essência da busca de relações equilibradas, harmoniosas. A retribuição era o modo de buscar-se o reequilíbrio dos laços, das relações. Há o tempo de dar e o tempo de receber. É preciso respeitar as circunstâncias. Uma retribuição imediata pode assemelhar-se a uma recusa. E nada envenena mais uma relação do que o rechaço de uma dádiva sincera. É interessante notar que talvez não seja mero acaso o fato de uma mesma palavra - gift - significar tanto "presente" quanto "veneno", dependendo da língua que a acolhe: em inglês, é presente; em alemão, é veneno; em holandês, é tanto presente quanto veneno... Uma retribuição imediata também pode sugerir uma troca de equivalentes. Uma aparência mortal quando se oferece um presente, cuja etiqueta com preço apressamonos a arrancar, cujo valor econômico procuramos, muitas vezes, disfarçar. 
A verdadeira doação, a dádiva efetiva é sinceramente generosa mas faz parte de sua natureza certa dissimulação igualmente generosa: quem recebe, se diz "obrigado" (a reconhecer a superioridade, a retribuir para reequilibrar a relação); quem dá, diz "por nada", ou "de nada", ou "não se sinta obrigado, isto não é nada". A circunstância da retribuição precisa ocorrer de modo natural, na convivência enriquecida pelos laços criados.

Em suas análises sobre o dom em sociedades pré-mercantis, Mauss foi premonitório em muitos de seus insigths, ao registrar a permanência de relações dadivosas no seio de sociedades marcadamente mercantis. Quando escreveu seu Essai sur le don (1922), nem de longe o mercado havia se imposto como forma quase exclusiva de circulação de bens. Hoje, poder-se-ia mesmo afirmar que, na sociedade em que vivemos, tudo parece estar à venda, a economia transformou tudo, ou quase tudo, em mercadoria. Apenas em alguns âmbitos, cada vez mais restritos, discute-se a legitimidade da submissão aos pressupostos do mercado: a Saúde e a Educação são os exemplos mais candentes. Por outro lado, dificilmente uma economia de mercado, mesmo a mais pujante, resistiria a uma eliminação de simulacros de motivos para a circulação de dádivas (falsas), de dons (corrompidos), de simples pretextos para a circulação de presentes, como soem transformar-se os notórios "dia das mães", "dia dos pais”, "dia das crianças", entre outros. Também ocorre com muita freqüência certa redução no significado de comemorações de diferentes tipos, envolvendo tanto atividades esportivas como religiosas ou políticas, convertidas, quase sempre, em meros pretextos para a circulação de presentes ou de bugigangas.

Insistimos em que, ao pensar-se o conhecimento como um bem, dificilmente se pode entender seu modo natural de circulação, como o que se realiza na relação professor/aluno, ou orientador/orientando, sem o recurso à dimensão dadivosa. Não se trata de negar sua dimensão mercantil, mas de não reduzilo a tal dimensão.

Nossa hipótese básica é a de que o desequilíbrio crescente na distribuição de riquezas decorre fundamentalmente de uma crise na idéia de valor, diretamente associada a uma ainda mal digerida transformação do conhecimento no principal fator de produção. Se o mercado foi revolucionário a seu tempo, significando a liberdade de escolha e a independência relativamente aos laços e às hierarquias previamente determinadas pela estrutura social, paulatinamente ele se transformou numa grande prisão, ou no único laço, que aprisiona tanto os que estão dentro quanto os que estão fora dele. O conhecimento como teoria, como visão que leva à compreensão somente pode ter seu valor devidamente apreciado se não se olvidar o recado do poeta (Antonio Machado):

"Todo necio

Confunde valor y precio". 
Naturalmente, a crise na idéia de valor, especialmente quando referida à insuficiência do par valor de uso/valor de troca na referência ao conhecimento, não pode ser ultrapassada por meio do retorno às dinâmicas pré-mercantis. Mas também não pode ser equacionada ignorando-se certas dimensões do conhecimento insuficientemente contempladas pelas dinâmicas mercantis.

Algumas tentativas extremamente engenhosas de escapar dos paradoxos a que conduziu o tratamento do conhecimento como um bem no sentido industrial têm sido continuamente realizadas. Pode ser esclarecedor comentar algumas delas, como a de Boisot (1998). Ainda que se situando estritamente dentro dos limites do mercado, com todas as pressuposições que o configuram, ela oferece alguns elementos interessantes no sentido de mapear tentativas de ultrapassagem da perspectiva mercantil. Em Knowledge assets, Boisot caracteriza o conhecimento como um ponto em um espaço com três dimensões. Para analisar o valor do conhecimento, considera um sistema formado por três eixos, com escalas crescentes de zero a $100 \%$.

Um dos eixos representa a dimensão abstrato/concreto: quanto mais diretamente vinculado a um único contexto, a uma determinada situação, menos valioso é o conhecimento; quanto mais abstrato, no sentido de que as relações percebidas/estabelecidas são pertinentes a múltiplos contextos, mais valioso é o conhecimento. Exemplificando com algum exagero mas sem falsificação, se alguém sabe que 3 abacaxis +4 abacaxis $=7$ abacaxis, mas não consegue saber $o$ resultado de 3 bananas +4 bananas, então seu "conhecimento" vale muito pouco; conhecer que $3+4=7$ exige que tal relação seja reconhecida em todos os contextos que possam ser imaginados.

Um outro eixo representa a dimensão não-codificado/codificado: quanto mais codificado, mais traduzido em palavras ou símbolos gráficos, mais valioso é o conhecimento. Ainda que tal dimensão possa se assemelhar à anterior, é possível uma distinção básica: um conhecimento pode ser vinculado a um contexto, mas ainda assim, pode ser passível de um registro escrito, de uma descrição pormenorizada, por exemplo, de todas as etapas para realizar determinada tarefa; por outro lado, um conhecimento pode transitar entre diferentes contextos apoiado exclusivamente pela experiência de quem o pratica, sem qualquer registro escrito, sem qualquer possibilidade de transferência para outras pessoas.

É no terceiro eixo, no entanto, que a perspectiva mercantil aflora com nitidez: trata-se do eixo difundido/não-difundido. Nesse sentido, quanto mais difundido é um conhecimento, menos valor ele tem (ou dele pode ser extraído); quanto menos difundido, mais valioso, ou maior é a possibilidade de exploração no mercado. Na perspectiva de Boisot, portanto, o valor mínimo do conhecimento ocorre quando se sabe algo apenas de modo vinculado a uma situação prática, não existem registros escritos que viabilizem a utilização de tal conheci- 
mento por outras pessoas, e o que é "pior": todo mundo sabe; o valor máximo ocorre quando temos um conhecimento abstrato, codificado e ainda não difundido. Tudo isso parece muito bem equacionado, possibilitando a construção de estratégias de otimização na extração de valor do conhecimento; no que se refere ao último eixo, tudo funciona, no entanto, em sentido oposto ao dos objetivos educacionais, que visam à partilha de significações e são regulados por valores maiores.

Apesar de a perspectiva de Boisot resolver algumas das dificuldades práticas diagnosticadas na atribuição de valor ao conhecimento, ela apenas reforça a sensação de que o sentido geral do movimento de acumulação e de desigualdades crescentes seria, em certo sentido, aperfeiçoado.

Já há alguns anos, a busca de saídas para as dificuldades resultantes da rigidez cartesiana na hierarquia universitária, no encadeamento lógico das decisões em colegiados de diversos níveis, tem conduzido a um aumento expressivo no número de Fundações, que possibilitam maior agilidade nas decisões e maior flexibilidade em amealhar recursos para diversas atividades acadêmicas. Uma teoria - no sentido de uma visão que leve à compreensão - para iluminar a convivência e as inter-relações entre as duas estruturas - a acadêmica e a das Fundações - ainda está por ser esboçada, sendo inevitáveis alguns conflitos de interesses e de valores, que, sem ela, só tenderão a aumentar. A questão das Fundações, no entanto, é apenas a ponta visível de um iceberg imenso: não se trata de uma simples questão de gestão de recursos, mas de uma complexa questão de atribuição de valor ao conhecimento.

Para uma resposta a tal questão, parece necessário esboçar uma teoria do valor que promova uma confluência entre as perspectivas intra e extramercantis, e dê conta da natureza muito especial do "bem" que efetivamente é o conhecimento. Enquanto tal teoria não se configura, a organização do conhecimento na Universidade tendo em vista exclusiva ou preponderantemente os elementos que caracterizam a forma mercantil de circulação de bens é uma empreitada cheia de riscos, na qual o fundamental pode estar se transformando em mero acessório, e os coadjuvantes menores podem estar usurpando o lugar dos verdadeiros protagonistas, na grande representação / construção / preservação do conhecimento e da cultura.

\section{Referências bibliográficas}

APPADURAI, Arjun (ed.). La vida social de las cosas: perspectiva cultural de las mercancías. México, Grijalbo, 1991.

BOISOT, Max H. Knowledge assets: securing competitive advantage in the Information Economy. New York, Oxford University Press, 1998. 
BOULDING, Kenneth E. La economía del amor y del temor. Una introducción a la economia de las donaciones. Versión espanhola de Isabel Verdeja Lizama. Madrid, Alianza Editorial, 1976.

CAILLÉ, Alain. Nem holismo nem individualismo metodológicos. Marcel Mauss e o paradigma da dádiva. Trad. Beatriz Perrone Moisés. Revista Brasileira de Ciências Sociais, v. 13, n. 38, p. 5-38, out. 1998.

CONNOR, Steven. Teoria e valor cultural. Trad. Adail Ubirajara Sobral e Maria Stela Gonçalves. São Paulo, Loyola, 1994.

DARNTON, Robert. O Iluminismo como negócio : história da publicação da "Enciclopédia". Trad. Laura T. Motta e Maria L. Machado. São Paulo, Cia. das Letras, 1996.

DESCARTES, René. Discurso sobre o Método [1647]. São Paulo: Hemus, 1978.

FITOUSSI, Jean-Paul \& ROSANVALLON, Pierre. A nova era das desigualdades. Trad. Miguel Serras Pereira. Oeiras, Portugal, Celta Editora, 1997.

FROW, John. Cultural studies \& Cultural value. New York, Clarendon Press/Oxford University Press, 1995.

GODBOUT, Jacques. O espírito da dádiva. Trad. José Pedro Cabrera. Lisboa, Instituto Piaget, 1997.

Introdução à dádiva. Trad. Beatriz Perrone Moisés. Revista Brasileira de Ciências Sociais, v. 13, n. 38, p. 39-53, out. 1998.

GODELIER, Maurice. L'énigme du don. Paris, Fayard, 1996.

KUTTNER, Robert. Tudo à venda: as virtudes e os limites do mercado. Trad. Claudio Weber Abramo. São Paulo, Cia. das Letras, 1998.

MATUCK, Arthur. Semion: um símbolo para a informação liberada. São Paulo, ECAUSP, Arte e Ciência/Qualidade de Vida, p. 55-68, 1997.

MAUSS, Marcel. Ensaio sobre a dádiva [1922]. Trad. António Filipe Marques. Lisboa, Edições 70, 1988.

MÉDA, Dominique. Qu'est-ce que la richesse? Paris, Alto/Aubier, 1999.

PAZ, Octavio. El precio y la significación. In: Puertas al campo. Barcelona, Seix Barral, 1989, p. 205-233.

POLANYI, Michael. Personal knowledge: towards a post-critical philosophy [1958]. London, Routledge \& Kegan Paul, 1969. . The tacit dimension. Gloucester, Mass, Peter Smith, 1983.

POPPER, Karl R. Conhecimento objetivo. Trad. de Milton Amado. São Paulo, Edusp/ Itatiaia, 1975.

REICH, Robert. Otrabalho das nações. Trad. José Maria Castro Caldas. Lisboa, Quetzal Editores, 1996. 
RUBIN, Isaak Illich. A teoria marxista do valor. Trad. José Bonifácio de S. Amaral Filho. São Paulo, Editora Pólis, 1987.

SCHAFF, Adam. A sociedade informática. Trad. C. E J. Machado e L. A. Obojes. São Paulo, Unesp/Brasiliense, 1990.

SEN, Amartya. Sobre ética y economia. Trad. Angeles Conde. Madrid, Alianza, 1991.

SVELBY, Karl Erik. A nova riqueza das organizações: gerenciando e avaliando patrimônios de conhecimento. Trad. Luiz Euclydes T. Frazão Filho. Rio de Janeiro, Campus, 1998.

TOCQUEVIlLE, Alexis de. A democracia na América. Tradução de Neil Ribeiro da Silva. São Paulo, Edusp/Itatiaia, 1977.

Nílson José Machado, membro do Conselho Deliberativo do Instituto de Estudos Avançados da USP e do Conselho Editorial de ESTUDOS AVANÇADOS, é professor da Faculdade de Educação da Universidade de São Paulo. 